Please cite as: Greifeneder, R., Bless, H., \& Kuschmann, T. (2007). Extending the brand image on new products: The facilitative effect of happy mood states. Journal of Consumer Behavior, 6, 19-31. doi: 10.1002/cb.205

Address correspondence to: rainer.greifeneder@unibas.ch

Extending the brand image on new products:

The facilitative effect of happy mood states

\author{
Rainer Greifeneder
}

Herbert Bless

Thorsten Kuschmann 


\begin{abstract}
Investigates the influence of mood and brand favorability on the evaluation of brand extensions. It is argued that affective states have an impact on the likelihood that the evaluation of a new product is based on the implications of the brand rather than on the implications of the features of the new product. Specifically, participants reported more positive evaluations of a new product when it was introduced by a positive rather than a negative brand - and this differential impact of category information was more pronounced for participants in a positive compared to a neutral or a negative mood.
\end{abstract}

Word count: 98

Keywords brand extension, mood, general knowledge structures, evaluation, category 


\section{Extending the brand image on new products: The facilitative effect of happy mood states}

In light of skyrocketing costs for the introduction of new products, brand extensions - the deployment of an existing brand to launch a new product that is not part of the original product family or category - have become an increasingly popular strategy (Aaker, 1991). Estimates of the ratio of product extensions run as high as 80 percent, suggesting that fourfifth of all new products are marketed as an extension to an existing brand (Rangaswamy et al., 1993). Well-known examples are Camel footwear, Calvin Klein perfumes, or Virgin (Atlantic) air transportation, all capitalizing on an established and highly valued brand name to market a new product (category).

The assumed benefits of brand extension stem from the reduction of risks associated with the introduction of a new product (Aaker and Keller, 1990). Indeed, costs for the development of new products are high, whereas chances for their success are generally low, given the high number of new products introduced each year and a substantial flop rate. From this perspective, any means for markedly reducing the risks associated with the introduction of a new product is welcome and brand extension is one of them.

At least two processes are assumed to be the basis of the described reduction of risks associated with brand extensions. First, an evaluative transfer from the brand to the new product is assumed (Aaker and Keller, 1990). Specifically, the brands' core features (for example, quality, attractiveness, spirit) are said to be attributed to the extension, thereby giving advance credit to a product not yet known to the market. Second, introducing a new product under the umbrella of an existing brand provides security and guidance to customers. Indeed, customers become insecure and reluctant to choose when faced with a growing number of alternatives (lyengar and Lepper, 2000). This reluctance may be reduced by marketing products as extensions to existing brands that people already know and feel good or safe about. In sum, a number of reasons speak for the strategic importance of brand extensions, and their increasing popularity during the last decades provides robust evidence for this theoretical supposition (Aaker, 1991). 
Even though brand extensions are attractive ways to introduce new products, not every brand extension is deemed to be successful. As a matter of fact, many brand extensions fail. For instance, Levi Strauss \& Co.'s move to introduce suits with a Jeans brand label was a huge and expensive flop. Addressing such an alarming flop rate, research has investigated conditions that influence the success of brand extensions (for reviews, see Aaker, 1991; Shocker et al., 1994). Researchers studying the processes underlying successful and less successful brand extensions have conceptualized brands as categories composed of products that are marketed through a common brand name (Boush and Loken, 1991; Boush, 1993). Each brand category is associated with certain characteristics (e.g. quality, personality features) that are attributed to its exemplars. The strategy of brand extension capitalizes on this evaluative transfer, hoping that the positive characteristics associated with the brand will be transferred to the new product.

Not surprisingly, the likelihood of such an evaluative transfer strongly depends on a number of factors. First, it has been argued that the similarity in the features of the core brand and of the new product is of crucial importance (Aaker, 1991; Boush and Loken, 1991; Keller and Aaker, 1992). Evaluative transfer from the brand to the product has been shown to be most likely if the new product is regarded as a category (brand) exemplar. Conversely, if a new product is not regarded as an exemplar of the brand category, evaluative information is unlikely to be transferred to the new product. In this respect, research has investigated factors that increase or decrease the perceived similarity of the features, and whether or not a particular new product is assigned to a brand (e.g. Park et al., 1991).

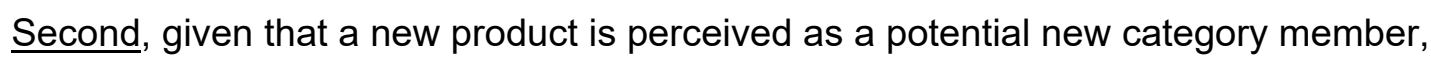
factors influencing the use of categorical information for evaluative purposes have to be taken into account as well. Indeed, for a brand extension to succeed, it is not enough that the new product is perceived as a category member - the information associated with the brand also has to be transferred from the brand to the new product. In that respect, factors determining the use of category membership information in judgment formation are of crucial importance. As in other domains (for example stereotyping) process factors may determine 
the influence of category versus (new) exemplar information. The existing literature suggests that the implications of a category should have a particularly strong impact if either processing motivation or processing capacity is low, whereas new exemplar information should be more influential if both processing capacity and processing motivation are high. For example, Sanbonmatsu and Fazio (1990) demonstrated that consumers' judgments reflected the implications of product features if they had sufficient motivation and capacity. If either motivation or capacity were low, the features of the new product rather than the attributes of the brand influenced judgments about the new product.

\section{Mood as a moderator of brand extension evaluations}

Many advertising strategies seem to rely heavily on the idea that ads are more effective, when they induce a positive affective state (for the role of mood in advertising effectiveness see, for example, Batra and Stayman, 1990). Given the seeming omnipresence of positive affect in advertising campaigns, and given the present focus on brand extension, the question arises how affective states may influence the success of the brand extension approach. In this respect, three different, but related, aspects can be distinguished.

First, it has been suggested that mood influences the interpretation of brand information at the time of initial encounter, with positive mood increasing the extremity of evaluations (Adaval, 2003; for a different position see Bower, 1981). This hypothesis is based on the notion that positive mood enhances the reliance on general structures (Bless et al., 1996a) and the elaboration of the features associated to them (Adaval, 2003). Since brands may be conceptualized as general knowledge structures (Boush and Loken, 1991), positive mood should result in an increased elaboration of the components associated to brands, and consequently in more extreme perceived implications of brand information. However, as the assumed mechanism hinges on intensive elaboration, the hypothesized extremity effect should vanish in conditions of low processing intensity. The results of three studies (Adaval, 2003) support these hypotheses, suggesting that the initial apprehension of a brand is more extreme for people in happy compared to sad moods, but only in conditions of high processing capacity. Furthermore, the reported parameter estimates suggest that this initial 
apprehension influences extensions judgments, and not differential use of brand versus attribute information.

$\underline{\text { Second, it has been argued that affective states influence categorization processes, }}$ thereby altering the likelihood that a given exemplar (here the new product) is assigned to an existing category (here the core brand) (for example, Isen and Shalker, 1982). In particular, research by Isen and colleagues (for an overview see Isen, 1987) indicates that individuals in happy moods perceive more similarities between an exemplar and a category. As a consequence, happy moods facilitate flexible categorization processes and increase the likelihood that even untypical exemplars are assigned to a category (Isen and Daubman, 1984), a process which also results in more clustering under happy moods (Bless et al., 1992; Isen et al., 1987; for further evidence regarding this kind of flexibility in happy individuals see Murray et al., 1990).

Based on these general ideas on categorization flexibility, research by Barone, Miniard, and Romeo (2000) has addressed the impact of incidental positive affect on the likelihood that a particular extension is categorized into the core brand and is subsequently evaluated more positively. According to their findings, positive moods, relative to neutral moods, enhance the evaluation of moderately similar brand extensions to a positively evaluated core brand. For very dissimilar or very similar products, however, no bolstering effect of mood was observed. The authors account for this finding by assuming that the enhanced categorization flexibility, as suggested by Isen and Daubman (1984), should be of little influence if the degree of similarity between the product and the brand is extremely low (very dissimilar product) or high (very similar product).

Further research reported by Barone and Miniard (2002) confirms the impact of happy moods on the likelihood that a moderately similar extension is assigned to a positive core brand and is subsequently evaluated more positively. In addition, Barone and Miniard (2002) presented evidence that positive (versus less positive) mood states enhance extension evaluations only for desirable core brands, whereas no effects were reported for undesirable core brands. The explanation for this effect is based on the work of Isen, Niedenthal, and 
Cantor (1992), which suggests that increased categorization flexibility emerges only for positively-valenced category information. This asymmetry between positively- versus negatively-valenced category information is due to the differential impact of mood states on memory retrieval. Specifically, it is argued that positive mood mainly cues positivelyvalenced information in memory (and vice versa for negative mood) (e.g. Bower, 1981). Being in a positive mood therefore increases the accessibility of positive material (e.g. desirable brand features), whereas the accessibility of negative materials (e.g. undesirable brand characteristics) remains unchanged. Hence, happy mood states should result in increased categorization flexibility only for positive material.

Third, in addition to mood influencing the initial categorization processes, mood may also influence whether or not the implications of a category are used. Even if an exemplar is clearly assigned to a category, this does not necessarily imply that the category information must be used when the exemplar is evaluated. Indeed, research from the stereotyping domain has consistently demonstrated that although a target is clearly identified as belonging to a category, which would allow for category-based processing, individuals may nevertheless rely on individuating information to evaluate the target (cf. Fiske and Neuberg, 1990). In this respect, it has been shown that a given category information is most likely to be used when either processing motivation (Neuberg and Fiske, 1987) and/ or processing capacity (e.g. Bodenhausen, 1990) are low (for an application to the consumer domain see Sanbonmatsu and Fazio, 1990). From this perspective, the influence of brand information should be most likely under conditions of reduced processing intensity. Note that this conclusion is seemingly at odds with Adaval's (2003) hypothesis of more extreme evaluations in situations of high processing intensity.

Interestingly, evidence from very different domains suggests that positive affect increases the likelihood that happy individuals rely on available category information, whereas sad or neutral mood individuals are more likely to account for the implications of a given exemplar. For example, Bodenhausen, Kramer, and Süsser (1994a) demonstrated that stereotypic judgments increased when participants were in a happy mood. Specifically, when provided 
with both category and individuating information, judgments of happy individuals reflected the implications of the category information more than judgments of neutral or sad participants (Bodenhausen et al., 1994b). These and other related findings (e.g. Bless et al., 1996b; Krauth-Gruber and Ric, 2000; Park and Banaji, 2000; Ric, 2004) demonstrate an increased reliance on the category information under happy moods, unless the individuating information is extremely different from the category information (Krauth-Gruber and Ric, 2000). Various accounts have been proposed for these effects and other related evidence suggesting an increased use of heuristics under happy moods. In particular, it has been argued that happy moods decrease processing capacity (e.g. Mackie and Worth, 1989) or processing motivation (e.g. Schwarz, 1990; Wegener and Petty, 1994), which in turn increases the reliance on category information. Other accounts refrain from the assumption that happy moods cause processing deficits (Bless, 2001; Bless et al., 1996a) and hold that happy moods increase the reliance on general knowledge structures (here brand information) without causing capacity or motivational deficits (given that the present research does not address the differences between these accounts, this issue will not be discussed further; for a discussion see the contributions in Martin and Clore, 2001).

Given the robust finding of an increased reliance on category information under happy moods, it seems justified to transfer the implications of these findings to brand extensions. A straightforward prediction that can be derived from such a transfer holds that the core brand information should be particularly influential when individuals are in a happy mood, rather than a neutral or sad mood. To test this assumption, we confronted individuals in either a happy, neutral, or sad mood with a new product. This product was clearly assigned to a brand toward which recipients held rather positive or rather negative attitudes. We hypothesized that

H1: A new product is evaluated more positively when assigned to a favorable rather than an unfavorable brand.

H2: The impact of the brand information $(\mathrm{H} 1)$ is more pronounced under happy rather than under neutral or sad moods. Thus, a new product will be evaluated more in line with the 
implications of the core brand when individuals are in happy rather than in a neutral or sad mood.

H3: In line with these considerations, we further expected that the assimilation towards the core brand under happy moods $(\mathrm{H} 2)$ should emerge for both favorable and unfavorable brands - paralleling the impact of positive and negative stereotypes on target evaluations in the stereotyping domain. Therefore, seeming extensions to favorable brands should be evaluated more positively under happy compared to neutral or sad incidental mood states, and the reverse being true for unfavorable brands.

Going beyond existing research on affect and brand extension, the operationalization of the current project differs from previous ones in three important respects. First and foremost, brand and attribute information were presented as ostensibly real ads to create an experimental situation that more closely mirrors the way such information would be perceived outside the lab. This approach is noticeably different from previous ones that presented only descriptive information cues, such as the brand name and written text about potential extensions (e.g. Adaval, 2003; Barone et al., 2000). Note that this approach increased ecological validity, although we readily acknowledge that the chosen procedure does not fully establish it. Nevertheless, using ostensibly real ads instead of mere descriptive information seems to allow for more direct conclusions to the practitioner's world. Second, but for the very same reason, processing constraints were implemented during the presentation of brand and attribute information. Since ads are usually perceived in situations of low processing intensity (for instance while waiting for a bus, while reading a newspaper or while preparing dinner), and knowing the importance of processing intensity for the way judgments are formed (e.g. Chaiken and Trope, 1999), it seemed almost mandatory to create the experimental situation such that participants' processing intensity is low. For processing intensity to be low, either the motivation or the capacity to process, or both, need to be low (Chaiken and Trope, 1999; Petty and Cacioppo, 1986). Given that processing capacity can be severely impaired by reducing the time allotted for processing, limiting the ads' presentation time appeared to be a suitable way for reducing processing intensity. Note that 
for conditions as such, the extremity effect reported by Adaval (2003) should not occur, supposedly because elaboration is necessary for its appearance. In contrast, the hypothesized use of general knowledge structures remains a valid explanation. Third and finally, a positive and a negative mood condition as well as a neutral condition were created to allow for various comparisons of mood effects. Generally, having a neutral and a negative condition to compare the positive one with allows for a more complete picture and better understanding of the underlying processes.

\section{STUDY}

\section{Method}

\section{Design and Participants}

To investigate the influence of mood states on the evaluation of brand extensions, we conducted a 3 (positive, neutral or negative mood state) X 2 (favorable versus unfavorable brand) between-subjects factorial experiment. A total of 90 participants $(65.5 \%$ female, $34.5 \%$ male; age $\underline{M}=23.3, \underline{S D}=3.8$ ) were randomly assigned to the six factorial conditions. Participants were students from the University of Mannheim and participated in return for 2.5 EUR (approx. 2.5 USD at the time). Participants were seated separately in front of one out of $18 \mathrm{PC}$-workstations and were run in groups of up to 6 persons. Each PC-workstation was equipped with a mouse and a headset, however, no keyboards were provided.

\section{Procedure}

Upon arrival at the laboratory, participants were greeted by the experimenter and led to one of the computer stations. All of the subsequent instructions and tasks were presented in written form, either on the computer screen or as part of a paper-pencil-questionnaire.

The experiment was said to be about 'visual information processing.' The first two tasks were the manipulation of mood states and a respective manipulation test. Following this, the brand extension product together with the brand logo was presented for 20 seconds and subsequently evaluated. Afterwards, brand favorability was assessed and participants were 
asked to answer several socio-demographic questions. Finally, participants were thanked for their participation, formally debriefed, and given their reward for participation.

\section{Mood manipulation}

Participants' mood was manipulated using short digitalized film clips that had been successfully pre-tested. Positive mood was induced through a clip from "Charlie Chaplin The Rink" (3:24 Min), whereas negative mood was elicited with a clip from a BBCdocumentary "14 days in May" (3:38 Min). Participants in the neutral mood condition viewed a short documentary on the cubist Fernand Lèger (3:42 Min). All films were presented via the computer screen and the provided audio headset. To measure the success of this kind of manipulation, participants were asked to respond to the following three Likert-scaled items after viewing the film clips: "The film clip made my current mood $\ldots(1=$ worse, $9=$ better $)$ ", "At this moment l'm feeling ... (1 = very bad, 9 = very good)", "Currently l'm feeling ... $(1=$ sad, 9 = happy $)$.

\section{Product information}

In all conditions, the product to be evaluated was a family van (similar to cars like Dodge Caravan, Renault Espace, for example), allegedly produced by one of two car manufacturers with markedly different brand favorability. Since both car manufacturers did not have a van in their product line at that time, a van was regarded as a moderate extension to the brand, however clearly belonging to the respective category. Product information was presented as a professionally looking ad, with the respective brand logo clearly visible at the top and left of the product image, imbedded in the product slogan "A car for the whole family?" (top), and some non-specific information about the van (left). The ad was shown for 20 seconds in the center of the computer screen and participants were instructed to look at the ad carefully.

Participants' product evaluations were assessed after presentation of the ad, using seven 9-point Likert-scaled items, each ranging from 1 (does not apply) to 9 (strongly applies). All items started out with "In my opinion, the product just presented has the following characteristics ...". The characteristics to be evaluated were: secure, comfortable, 
prestigious, luxurious, elegant, exclusive, and classy (presented in fixed order). These characteristics were chosen based on a pre-test (see below), with maximum difference between the two makes being the selection criterion.

\section{Brand information}

The two makes selected were Mercedes and Škoda (a make produced in Czech Republic). Pre-testing at the University of Mannheim had shown that brand favorability differed strongly for the two makes, with Mercedes being evaluated more positively than Škoda. Specifically, pre-testing participants had indicated on 9-point Likert scales to what extent each of 20 pre-selected attributes (e.g. elegant, dynamic, fast) was associated with each of the two brands. Participants' ratings on all attributes were combined per brand to form favorability indexes (Mercedes, Cronbach's $\alpha=.83$; Škoda, Cronbach's $\alpha=.60$ ). These indexes were subjected to a t-test for paired groups, yielding a significant difference in favorability between Mercedes and Škoda, with the former being above and the latter below the scale-midpoint $(\underline{M}=6.77, \underline{S D}=.56$ versus $\underline{M}=4.17, \underline{S D}=.48 ; \underline{t}(9)=9.96, \underline{p}<.01){ }^{1}$

Furthermore, a product-brand-fit pre-test assured that the presented van was regarded as a similarly suitable extension to each of the two brands. Specifically, product-brand-fit was assessed with two items asking to what extent the presented van fits the brand image of Mercedes versus Škoda. Ratings on 9-point Likert scales were moderately high and did not differ between the two makes (Mercedes: $\underline{M}=5.1$, Škoda: $\underline{M}=5.0$; paired sample $\underline{t}<1$ ).

Based upon the reported pre-testing results, 7 out of the 20 characteristics were chosen for both the evaluation of the product (see above) and the manipulation check of brand favorability. Importantly, the seven items were selected such that the difference between the two makes was maximized $(\underline{t}(9)=10.86, \underline{p}<.01)$. The thus selected items were: secure, comfortable, prestigious, luxurious, elegant, exclusive, and classy (fixed order). Internal consistencies for the seven characteristics were similar for the two makes (Mercedes

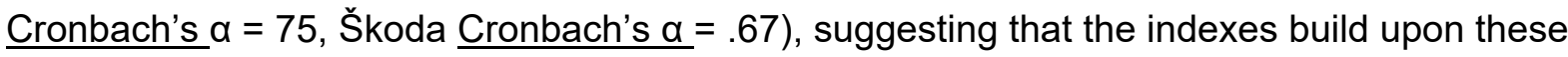
seven items were appropriate for both brands. 
Brand favorability was assessed after the product was evaluated. All items started out with: "In my opinion, the brand just presented has the following characteristics ...", followed by one of the seven selected characteristics. Again, items were 9-point Likert-scaled, ranging from 1 (does not apply) to 9 (strongly applies).

\section{$\underline{\text { Results }}$}

\section{Manipulation Check Mood}

The three mood manipulation items correlated to a high degree and thus were combined to form a single measure (Cronbach's $\alpha=.91)$. This measure was submitted to a onefactorial analysis of variance with mood as the independent variable, yielding a significant main effect for mood $(\underline{F}(2,87)=44.19, \underline{p}<.01)$. Planned contrast analyses further revealed that participants in the happy mood condition were in a better mood than participants in the neutral mood condition $(\underline{M}=7.04$ versus $\underline{M}=5.50$, $\underline{t}(87)=4.89, \underline{p}<.01)$, and that participants in the neutral mood condition were still in a better mood than participants in the negative mood condition $(\underline{M}=4.08$ for the negative mood condition, $\underline{t}(87)=4.51, \underline{p}<.01)$. Thus, the mood manipulation was entirely successful in creating mood states of different affective tones.

\section{Manipulation Check Brand Favorability}

Responses to the seven brand favorability checks were combined to form a single index (Cronbach's $\alpha=.96)$, which was entered into a 3 (mood) $\times 2$ (brand) between factorial analysis of variance. The results indicated a main effect only for brand, $\underline{F}(1,84)=196.45$, $\underline{p}<.01$, with Mercedes being evaluated more favorably than Škoda $(\underline{M}=7.24, \underline{M}=4.03$, respectively). Importantly, neither the mood main effect nor the mood $x$ brand interaction were of significance (all ps $>.19$ ), suggesting that the mood manipulation did not influence ratings of brand favorability per se. In sum, ratings of brand favorability strongly differed for Mercedes versus Škoda, with Mercedes being evaluated more favorably than Škoda. 


\section{Product evaluation}

Since the seven product evaluation items intercorrelated highly, items were combined to form a single measure ( $\underline{\text { ronbach's } \alpha}=.86)$. This measure was submitted to a $3(\mathrm{mood}) X$ 2 (brand) between factorial analysis of variance, yielding a significant main effect for brand, $\underline{F}(1,84)=11.90, \underline{p}<.01$. Overall, the ostensible Mercedes van was rated more favorably than the Škoda van $(\underline{M}=6.12$ versus $\underline{M}=5.12, \underline{t}(88)=3.29, \underline{p}<.01)$, thus supporting $H 1$. As predicted by $\mathrm{H} 2$, this main effect was qualified by a significant interaction effect of mood and brand $(\underline{F}(2,84)=4.55, \underline{p}<.02)$, suggesting that mood differentially influenced the use of brand information for product evaluation (see Figure 1). Specifically, differential effects between the Mercedes and the Škoda van were strongest for happy participants, $\underline{M}=6.39$ versus $\underline{\mathrm{M}}=4.64, \underline{\mathrm{t}}(84)=4.35, \underline{\mathrm{p}}<.01$, and least for sad participants, $\underline{\mathrm{M}}=5.66$ versus $\underline{M}=5.58, \underline{t}(84)<1$, with neutral mood participants falling in between, $\underline{M}=6.31$ versus $\underline{M}=5.73, \underline{t}(84)=1.44, \underline{p}>.15$. This pattern of findings clearly supports the assumptions summarized in $\mathrm{H} 2$.

Insert figure 1 about here

Given that brand information is mainly used by people in happy moods, it was further hypothesized that the product extension to the favorable make (Mercedes) was better evaluated in a positive versus negative mood state $(\mathrm{H} 3)$. Confirming this hypothesis, a planned contrast analysis revealed a significant difference between the evaluation of the Mercedes van in the positive compared to the negative mood condition $(\underline{t}(84)=1.82, \underline{p}<.04$, one-tailed). Conversely, it was assumed that the extension to the unfavorable brand (Škoda) should be evaluated more negatively in a positive than in a negative mood state. Again, results confirm this hypothesis, in that the Škoda van was rated less favorably by participants in the positive compared to the negative mood condition $(\underline{t}(84)=2.34, \underline{p}<.02$, one-tailed). 


\section{DISCUSSION}

The current paper set out to test the influence of mood states on brand extensions. Given the omnipresence of mood states and their known value for marketing, as well as the popularity of brand extensions as strategic marketing instrument, addressing this question appears to be a worthwhile endeavor. The results presented hold that incidental mood states may powerfully determine the extent to which brand information is used in evaluating extension products. In particular, brand information was shown to be most influential under happy mood states, while no such influence occurred for sad mood states.

Brands have been conceptualized as categories, with the perceived similarity between the brand and its potential extension products influencing the extent of evaluative transfer (Aaker and Keller, 1990; Boush and Loken, 1991; Keller and Aaker, 1992). However, as research from very different domains has demonstrated, because something is regarded as part of a category does not necessarily imply the use of category information for exemplar evaluation (Fiske and Neuberg, 1990; Bodenhausen et al., 1994a; Sanbonmatsu and Fazio, 1990). Indeed, affect and cognition research strongly suggests that only positive mood states foster category-based evaluations, whereas negative mood states were shown to increase the influence of exemplar information (Bodenhausen et al., 1994a). Building upon this literature, strong reliance on brand (category) information was expected for happy moods, whereas little evaluative transfer was hypothesized for negative mood states, despite a pre-tested similarity between brand and extension product.

Results strongly confirm these assumptions. Overall, a more favorable car make (Mercedes) was evaluated more positively than a less favorable car make (Škoda). This effect was particularly pronounced for participants in a happy compared to a neutral or sad mood, suggesting that evaluative transfer from a brand to a similar exemplar is most likely for happy mood states. Furthermore, this conclusion is corroborated by an inspection of correlational evidence between the product and the brand evaluations. For negative mood, this correlation is not significant $(\underline{r}=.26)$, whereas a substantial interrelation emerges for positive mood $(\underline{r}=.71, \underline{p}<.01)$, with the respective correlation for neutral mood falling in 
between $(\underline{r}=.50, \underline{p}<.01)$. Finally, it is noteworthy that increased evaluative transfer from the brand to the product under happy mood was observed for both the favorable and the unfavorable brand.

In line with previous research on the interplay of affect and brand extensions (Barone et al., 2000; Barone and Miniard, 2002; Adaval, 2003) the current evidence strongly supports the notion that positive mood increases the impact of brand information on extension evaluations. Going beyond the existing literature, however, at least five implications of the current project seem noteworthy: First, whereas previous studies used only descriptions and labels to provide brand or attribute information, ostensibly real ads were presented in the current project. Although not completely mapping everyday life (e.g., difference between self-exposure versus presentation by experimenter), the present procedure thus mirrored many aspects of how ad information is most likely processed in natural settings. As the hypothesized effect of mood on the impact of brand information emerged even under these more realistic conditions, it seems fair to suggest that the reported results may also be of importance outside the laboratory. In fact, in light of the current and previous evidence, it appears to be a worthwhile endeavor to take the role of affect into account when strategically tailoring brand extensions. As the current study is first to allow for such a conclusion, we think the presented evidence to be an important contribution, both from a theoretical and practical viewpoint.

Second, to further establish more realistic conditions, participants' processing intensity was reduced to everyday levels. This was done by restricting the ads' presentation time. Compared to previous studies we thus created conditions that are most likely to occur outside the laboratory, more closely resembling the situations within which consumers will perceive brand and extension information when exposed to ads. Interestingly, while Adaval (2003) would have predicted a null-effect for such conditions due to the fact that elaboration is necessary for the extremity effect to occur, our findings demonstrate a strong mood effect. This seems to suggest that a different process than the extremity effect is at the roots of the current evidence, with the hypothesized differential use of category versus exemplar 
information being the most likely one. Such a conclusion is further supported by our finding that participants' mood did not influence judgments of brand favorability per se, as would have been the case if mood states were influencing the initial evaluative apprehension of brands (Adaval, 2003). Thus, at least two processes seem capable of producing the reported effect of mood on brand extension evaluations, and further research disentangling the two seems warranted. Meanwhile, it is important to note that positive mood increases the impact of brand information on extension evaluations (even) in everyday conditions, i.e. conditions that consumers are most likely to experience.

$\underline{\text { Third, }}$, the present study compared the impact of happy versus sad versus neutral mood states on the likelihood of evaluative transfer, thus adding to previous studies that compared only two of these states, respectively. The current evidence supports the hypothesis that evaluative transfer from the brand (category) to the extension product is unlikely for negative affect, again paralleling results in the stereotyping domain (Bodenhausen et al., 1994b). Beyond the theoretical implications, this finding may be of practical interest. Although it seems rather unlikely that an ad induces sad moods when promoting a new product, carryover effects from surrounding situational factors could have a detrimental influence. For example, if a commercial is embedded in a sad movie, this movie may constitute a powerful source of negative affect influencing the success of a brand extension ad.

Fourth, the results provide further support for the notion that happy moods increase reliance on category information (for an overview see Schwarz and Clore, 1996). Since reliance on category information can be conceptualized as heuristic processing, these findings are very much in line with evidence suggesting increased heuristic processing under happy moods. As mentioned above, the specific cause of the relationship between happy mood states and heuristic processing was not investigated in the current study. However, based on the existing affect and cognition literature, it may be assumed that a stronger reliance on general knowledge structures for happy compared to neutral or sad mood states is at its roots (Bless et al., 1996a). Contrary to the assumptions of capacity or motivational deficits, the notion of increased reliance on general knowledge structures would imply that 
despite a positive mood state, no assimilation effects emerge for extreme deviations between category and exemplar information, as suggested upon different reasoning by Aaker and Keller (1990; for parallel effects in the domain of stereotype research, see Krauth-Gruber and Ric, 2000).

Finally, the reported evidence clearly indicates an impact of the favorable as well as the unfavorable brand on product evaluation. Specifically, positive mood was associated with increased favorability ratings for the extension to a favorable brand, but decreased favorability ratings for the extension to an unfavorable brand. While this finding is in line with research in the stereotyping domain, it appears to conflict with the findings reported by Barone and Miniard (2002), which suggest that increased evaluative transfer under happy mood states is restricted to positive brands. This seeming contradiction is most likely due to the differential processes that were investigated. Whereas Barone and colleagues (2000; 2002) focused on the influence of mood states on the initial categorization process, the present research investigated the impact of mood states on the use of category information. In this respect, two aspects of the current study are noteworthy, since they rendered product categorization likely upfront and independently of the respective mood states: For one, the extension was clearly assigned to the category (logo presentation; a van being an automotive vehicle). Furthermore, pre-testing assured a substantial fit of features between the extension product and the brand, which was independent of the respective brands' favorability ratings.

To summarize, the current research demonstrates that both mood and the brand's favorability may determine the success of a brand extension strategy. Specifically, if people are in a positive mood state at the point-of-encounter, evaluative transfer from the brand to the extension product is most likely - and if the brand is evaluated positively, this evaluative transfer is prone to result in an enhancement of product judgments. To explain this effect, three different but related processes need to be distinguished, with their respective validity depending on various situational constraints, such as processing time, category availability 
and presentation format. It is up to future research to more fully understand in which conditions which process is most valid.

Three further issues seem worth to be pursued in future research. First, the processes underlying the reported effects should be more closely examined. Although we attempted to rule out rivaling explanations with our chosen procedure (e.g., by creating conditions of low processing intensity) we acknowledge that more processing evidence would further support the assumptions about the underlying mechanisms. In this respect, for example, collecting processing data in form of judgmental latencies would allow for more direct conclusions. Second, while the current research addressed the role of incidental mood states, future research might focus on integral affective states (for the difference between the two constructs, see Bodenhausen, 1993), too. For example, it seems plausible that happy mood states elicited by the respective product itself (integral affect) may trigger stronger assimilation effects than happy mood states that prevail from external sources (incidental affect). Finally, it appears worth to understand whether and how the observed effects on attitude judgments translate into actual product purchasing behavior. This latter aspect seems particularly interesting for the practitioner's world.

In sum, the present research suggests that evaluative transfer from the brand to the extension product is most likely for happy moods states. Therefore, the presented evidence provides another important element to the complex picture of mood influences on the perception of advertising in general (Batra and Stayman, 1990), and brand extension, in particular. 


\section{REFERENCES}

Aaker, D. A. (1991). Managing brand equity: Capitalizing on the value of a brand name. New York: Free Press.

Aaker, D. A., \& Keller, K. L. (1990). Consumer evaluations of brand extensions. Journal of Marketing, 54(1), 27-41.

Adaval, R. (2003). How good gets better and bad gets worse: Understanding the impact of affect on evaluations of known brands. Journal of Consumer Research, 30(3), 352-367.

Barone, M. J., \& Miniard, P. W. (2002). Mood and brand extension judgments: Asymmetric effects for desirable versus undesirable brands. Journal of Consumer Psychology, 12(4), 283-290.

Barone, M. J., Miniard, P. W., \& Romeo, J. B. (2000). The influence of positive mood on brand extension evaluations. Journal of Consumer Research, 26(4), 386-400.

Batra, R., \& Stayman, D. M. (1990). The role of mood in advertising effectiveness. Journal of Consumer Research, 17(2), 203-214.

Bless, H. (2001). Mood and the use of general knowledge structures. In L. L. Martin \& G. L. Clore (Eds.), Theories of mood and cognition: A user's guidebook (pp. 9-26). Mahwah, $\mathrm{NJ}$ : Lawrence Erlbaum Associates.

Bless, H., Clore, G. L., Schwarz, N., Golisano, V., Rabe, C., \& Wölk, M. (1996a). Mood and the use of scripts: Does a happy mood really lead to mindlessness? Journal of Personality and Social Psychology, 71(4), 665-679.

Bless, H., Hamilton, D. L., \& Mackie, D. M. (1992). Mood effects on the organization of person information. European Journal of Social Psychology, 22(5), 497-509.

Bless, H., Schwarz, N., \& Wieland, R. (1996b). Mood and the impact of category membership and individuating information. European Journal of Social Psychology, 26(6), 935-959.

Bodenhausen, G. V. (1990). Stereotypes as judgmental heurstics: Evidence of circadian variations in discrimination. Psychological Science, 1(5), 319-322.

Bodenhausen, G. V. (1993). Emotions, arousal, and stereotypic judgments: A heuristic model of affect and stereotyping. In D. M. Mackie \& D. L. Hamilton (Eds.), Affect, cognition, and stereotyping: Interactive processes in group perception. San Diego, CA: Academic Press, Inc.

Bodenhausen, G. V., Kramer, G. P., \& Süsser, K. (1994a). Happiness and stereotypic thinking in social judgment. Journal of Personality and Social Psychology, 66 (4), 621632.

Bodenhausen, G. V., Sheppard, L. A., \& Kramer, G. P. (1994b). Negative affect and social judgement: the differential impact of anger and sadness. European Journal of Social Psychology, 24(1), 45-62.

Boush, D. M. (1993). Brands as categories. In D. A. Aaker \& A. Biel (Eds.), Brand equity and advertising: Advertising's role in building strong brands (pp. 299-312). Hillsdale, NJ: Erlbaum.

Boush, D. M., \& Loken, B. (1991). A process-tracing study of brand extension evaluation. Journal of Marketing Research, 28(1), 16-28.

Bower, G. H. (1981). Mood and memory. American Psychologist, 36(2), 129-148.

Chaiken, S., \& Trope, Y. (1999). Dual-process theories in social psychology. New York: Guilford Press. 
Fiske, S. T., \& Neuberg, S. L. (1990). A continuum of impression formation from categorybased to individuating processing: Influences of information and motivation on attention and interpretation. In M. P. Zanna (Ed.), Advances in Experimental Social Psychology (Vol. 23, pp. 1-74). Orlando, FL: Academic Press.

Isen, A. M. (1987). Positive affect, cognitive processes, and social behavior. In L. Berkowitz (Ed.), Advances in experimental social psychology (Vol. 20, pp. 203-253). San Diego, CA: Academic Press.

Isen, A. M., \& Daubman, K. A. (1984). The influence of affect on categorization. Journal of Personality and Social Psychology, 47(6), 1206-1217.

Isen, A. M., Daubman, K. A., \& Gorgoglione, J. M. (1987). The influence of positive affect on cognitive organization. In R. Snow \& M. Farr (Eds.), Aptitude, learning and instruction: Affective and conative processes (Vol. 3). Hillsdale, $\mathrm{NJ}$ : Erlbaum.

Isen, A. M., Niedenthal, P. M., \& Cantor, N. (1992). An influence of positive affect on social categorization. Motivation and Emotion, 16(1), 65-78.

Isen, A. M., \& Shalker, T. E. (1982). The effect of feeling state on evaluation of positive, neutral, and negative stimuli: When you "accentuate the positive", do you "eliminate the negative"? Social Psychology Quarterly, 45(1), 58-63.

lyengar, S. S., \& Lepper, M. R. (2000). When choice is demotivating: Can one desire too much of a good thing?. Journal of Personality and Social Psychology, 79(6), 995-1006.

Keller, K. L., \& Aaker, D. A. (1992). The effects of sequential introduction of brand extensions. Journal of Marketing Research, 29(1), 35-50.

Krauth-Gruber, S., \& Ric, F. (2000). Affect and stereotypic thinking: A test of the mood-andgeneral-knowledge-model. Personality and Social Psychology Bulletin, 26(12), 15871597.

Mackie, D. M., \& Worth, L. T. (1989). Processing deficits and the mediation of positive affect in persuasion. Journal of Personality and Social Psychology, 57(1), 27-40.

Martin, L. L., \& Clore, G. L. (2001). Theories of mood and cognition: A user's guidebook: Lawrence Erlbaum Associates, Publishers.

Murray, N., Sujan, H., Hirt, E. R., \& Sujan, M. (1990). The influence of mood on categorization: A cognitive flexibility interpretation. Journal of Personality and Social Psychology, 59(3), 411-425.

Neuberg, S. L., \& Fiske, S. T. (1987). Motivational influences on impression formation: Outcome dependency, accuracy-driven attention, and individuating processes. Journal of Personality and Social Psychology, 53(3), 431-444.

Park, C. W., Milberg, S., \& Lawson, R. (1991). Evaluation of brand extensions: The role of product feature similarity and brand concept consistency. Journal of Consumer Research, 18(2), 185-193.

Park, J., \& Banaji, M. R. (2000). Mood and heuristics: The influence of happy and sad states on sensitivity and bias in stereotyping. Journal of Personality and Social Psychology, 78(6), 1005-1023.

Petty, R. E., \& Cacioppo, J. T. (1986). Communication and persuasion: Central and peripheral routes to attitude change. New York, NY: Springer.

Rangaswamy, A., Burke, R., \& Oliva, T. A. (1993). Brand equity and the extendibility of brand names. International Journal of Research in Marketing, 10, 61-75.

Ric, F. (2004). Effects of the activation of affective information on stereotyping: When sadness increases stereotype use. Personality and Social Psychology Bulletin, 30(10), 1310-1321. 
Sanbonmatsu, D. M., \& Fazio, R. H. (1990). The role of attitudes in memory-based decision making. Journal of Personality and Social Psychology, 59(4), 614-622.

Schwarz, N. (1990). Feelings as information: Informational and motivational functions of affective states. In E. T. Higgins \& R. M. Sorrentino (Eds.), Handbook of motivation and cognition: Foundations of social behavior (Vol. 2, pp. 527-561). New York: Guilford Press.

Schwarz, N., \& Clore, G. L. (1996). Feelings and phenomenal experiences. In E. T. Higgins \& A. W. Kruglanski (Eds.), Social psychology: Handbook of basic principles (pp. 433465).

Shocker, A. D., Srivastava, R. K., \& Ruekert, R. W. (1994). Challenges and opportunities facing brand management: An introduction to the special issue. Journal of Marketing Research, 31(2), 149-158.

Wegener, D. T., \& Petty, R. E. (1994). Mood management across affective states: The hedonic contingency hypothesis. Journal of Personality and Social Psychology, 66(6), 1034-1048. 


\section{FOOTNOTES}

${ }^{1}$ Since having similar measurement errors is a necessary precondition for paired sample t-tests, one may suspect that the difference in Cronbach's Alpha between the two attribute indexes might have distorted the presented results. However, given the significance of the reported effect $(t(9)=9.96)$, and given that in the main study only a reduced set of seven items with rather similar internal consistencies for the two attribute-indexes was used

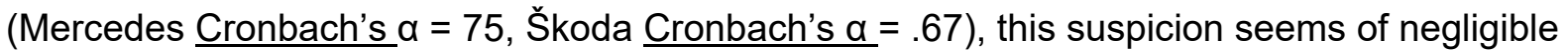
size. 


\section{FIGURE CAPTION}

Figure 1: Mean evaluations (with standard errors) of the extension product as a function of mood and brand. Range from 1 (negative) to 9 (positive), with 5 being the neutral midpoint.

\section{FIGURE 1}

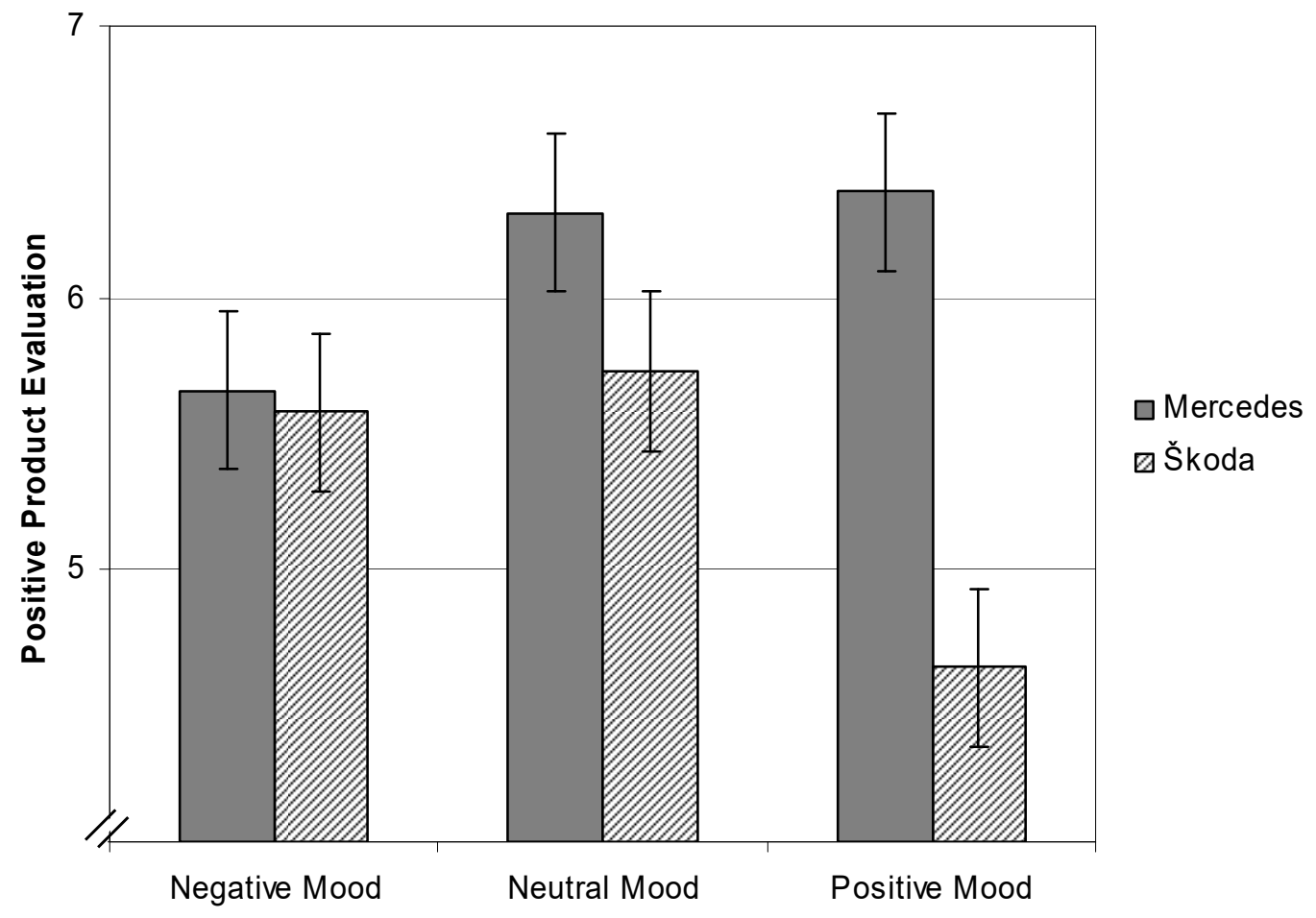

